\title{
Topic Study Group No. 50: In-Service Education, and Professional Development of Secondary Mathematics Teachers
}

\author{
Jill Adler, Yudong Yang, Hilda Borko, Konrad Krainer \\ and Sitti Patahuddin
}

\section{The Programme}

The aim of TSG 50 at ICME-13 was to share, discuss and advance knowledge and understanding of key aspects of research, policy and practice in the in-service education and professional development of secondary mathematics teachers. In TSG 50, there were a total of 97 contributions (19 Paper presentations, 49 Oral presentations and 29 Poster presentations) and well over 100 participants given this total does not include the TSG organizing team, and some paper co-authors.

During ICME-13 conference, the work of TSG 50 was organized into four main TSG Sessions, and these were supplemented by oral communication and poster sessions. The four main sessions each focused on key questions. Session 1 reported and reflected on A Survey of the Field of Research on Mathematics Professional Development. The session was chaired by Jill Adler, and focused on two key questions: Q1. What key research questions, theories and methods are used to study in-service education and professional development of secondary mathematics teachers? Q2. What are the accumulating results of research? What do we still not know or understand? What are the implications for policy and practice and across contexts?

Co-chairs: Jill Adler, Yudong Yang.

Team members: Hilda Borko, Konrad Krainer, Sitti Patahuddin.

\author{
J. Adler $(\square)$ \\ University of the Witwatersrand, Johannesburg, South Africa \\ e-mail: jill.adler@wits.ac.za \\ Y. Yang \\ Shanghai Academy of Educational Sciences, Shanghai, China \\ e-mail: mathedu@163.com \\ (C) The Author(s) 2017 \\ G. Kaiser (ed.), Proceedings of the 13th International Congress on Mathematical \\ Education, ICME-13 Monographs, DOI 10.1007/978-3-319-62597-3_77
}


Hilda Borko, Stanford University, USA, presented a "stimulus paper" entitled Research on Mathematics Professional Development. This paper is a review of research in the field, and Hilda's presentation was followed by reflective comments from each of the remaining TSG 50 Team Members. Konrad Krainer, reflected on the format of the study, in particular focusing on the research process, its strengths and absences. Yudong Yang, drew attention to the Asian perspective and specifically to important work that has been done on Lesson Study, an aspect of the field not dealt with directly in the review. Sitti Patahuddin emphasized the ICT perspective of professional development for secondary mathematics teachers. Jill Adler pointed out that research in the field of education development was not incorporated in the review, and was important to consider as there was evidence of failure in many developing contexts of professional development initiatives focused on reform, and as Chair of the session concluded with a short summary of TSG 50's first session, and introduction to the remaining sessions of the TSG for all participants.

The second main session focused on the question: Q3. What have we learned about secondary mathematics teachers' learning through participation in PD, related to beliefs, knowledge and practice? There were two parallel sessions, one chaired by Sitti Patahuddin, focused on teacher learning in relation to their knowledge, beliefs and practice; the other was chaired by Yudong Yang, and focused on teacher educator/facilitator/coach learning. The presentations' titles and their authors are the following, the first four in the teacher learning session and the remaining four in the teacher educator learning session:

- Enhancing reflective skills of secondary mathematics teachers via video-based peer discussions: a cross-cultural story (Karsenty, Ronnie; Schwarts, Gil).

- The challenges of upgrading mathematics teachers: a case study from one developing country (Kazunga, Cathrine; Bansilal, Sarah).

- Teachers noticing students' potentials while analysing video clips (Schnell, Susanne).

- Development of mathematical knowledge for teaching of mathematics teachers in lesson analysis process (Baki, Müjgan).

- Fostering an intimate interplay between research and practice: Danish "maths counsellors" for upper secondary school (Jankvist, Uffe Thomas; Niss, Mogens).

- Opportunities for learning of secondary math teacher leaders in the context of a video club (Kobiela, Marta; Savard, Annie; Merovitz, Scosha; Chandrasekhar, Vandana).

- District coaches facilitating teachers' use of inquiry-oriented math textbooks: a professional development design study (Boufi, Ada).

- The role of facilitator feedback in shaping teacher attention and response to student thinking (Glennie, Corinne Rose; Brizuela, Bárbara).

The third main session focused on the question: Q4. What innovative professional development programs with/without ICT for in-service mathematics teachers at secondary level have been developed and implemented in different cultural contexts? What is the role of professional learning communities in these programs, 
including online communities? Here too there were two parallel sessions, chaired respectively by Jill Adler and Hilda Borko. One focused on a range of Professional Development programs including a specific focus on Learning and Lesson Study initiatives; and the other focused on those with a specific ICT focus. The presentations' titles and their authors are as following, with the last three on ICT:

- Learning study and the idea of variation and critical aspects of learning (Runesson, Ulla).

- Supporting teachers in ambitious mathematics teaching (Ronda, Erlina).

- (In)visible theory in mathematics teacher education (Österling, Lisa).

- Developing mathematical identity and 'understanding mathematics in depth': conceptions of secondary mathematics teachers (Stevenson, Mary).

- Pedagogical explorations integrated with practical experiences transforming teachers' knowledge (Niess, Margaret Louise; Gillow-Wiles, Henry).

- An online course for inservice mathematics teachers at secondary level about mathematical modelling (Bosch, Marianna; Barquero, Berta; Romo, Avenilde).

- Virtual ethnographic intervention through facebook group: a case study in a disadvantaged context (Patahuddin, Sitti; Lowrie, Tom).

The fourth main session (chaired by Konrad Krainer and concluded by Jill Adler) focused on the question: Q5. What do we know about the impact, sustainability and scalability of PD programs? What are the various ways in which sustainability, scalability and effectiveness are defined and then assessed? The presentations' titles and their authors are as following:

- Attending to context when designing mathematics professional development with scale in mind (Smith, Thomas M.; Borko, Hilda; Sztajn, Paola).

- Researching the sustainability of professional development programmes (Zehetmeier, Stefan).

- Improving teachers' mathematical content knowledge and the impact on learner attainment (Pournara, Craig).

- Transformative cascade model for mathematics teacher professional development (Lin, Fou-Lai; Yang, Kai-Lin; Wang, Ting-Ying).

Supplementing these main TSG sessions, were six parallel Oral Communications sessions where 49 papers were presented and discussed; and two sessions for 29 Poster papers (due to the pages' limitation, the titles and presenters of Oral Communication and Poster will not be listed here). It is also not possible to communicate the richness of research and ideas presented and discussed. We nevertheless mention some exemplary aspects that were highlighted.

In the review of the field presented in session 1 most studies examined primarily utilized qualitative methods, which can offer detailed accounts of PD models and rich descriptions of teachers' experiences in the PD while providing proof of concept that the PD design can effectively support teacher learning. Opportunities to analyze excerpts of classroom video or mathematical tasks were provided as examples of contexts and practices promoting learning in professional communities. Knowledge of student mathematical thinking was drawn attention to as critical 
for teacher learning. In addition, PD facilitators' learning was identified as a new focus of research in the field. These studies demonstrated the continued value of foundational, exploratory, development, and design research for growing the knowledge base on mathematics PD. Still, very few studies investigated causal links between participation in PD and teacher or student outcomes. In addition research that examines what it takes to bring these programs to scale on the one hand, and that compares the effectiveness of different mathematics professional development programs on the other, needs further development.

Secondary mathematics teachers' professional development programs in specific contexts were introduced and discussed in TSG 50. The analysis of sustainable effects is crucial for short-term and long-term programs. The way in which sustainable impacts were researched, the theoretical models and empirical findings were discussed. More evaluation and analysis of sustainable impacts are needed in the future, along with sustainability in teacher education.

The use of technology in mathematics professional development was also a popular topic in TSG 50. Here foci were on the use of technology as interaction tools in and for mathematics teachers' professional development, as it provides resources and platforms for teachers at scale; and on digital technology as an interactive way to support mathematics teachers' learning that has great potential prospect. However, research on the effectiveness of using technology as a mode of interactions is limited. Further research is also needed to understand the possible challenges of the transformation in technology-based programs, such as the design of digital PD to match with the context and needs of teachers, the roles of the facilitators, the specialized pedagogy to conduct digital mathematics professional development, and the utilization of big data in understanding digital PD effectiveness.

In conclusion, TSG 50 was a learning space where mathematics professional development programs were overviewed theoretically, using different analytical frameworks, as well as empirically. New programs for secondary mathematics teachers' professional development in specific context were shared, including some attention to Lesson study, though less so in the Asian context; and all of these with or without information and communication technology. Presentations explored teacher educators' role and their knowledge and skills promotion within diverse backgrounds; and the impact of sustainability of professional development. Others introduced technology-based professional development programs. Some presenters put forward more research questions, including the prospective of using big data to better understand the effectiveness of teachers' PD. However, we are still short of evidence-based studies and of tools for measuring and evaluating teachers' learning. These areas remain a challenge for researchers in this field.

Open Access Except where otherwise noted, this chapter is licensed under a Creative Commons Attribution 4.0 International License. To view a copy of this license, visit http://creativecommons. org/licenses/by/4.0/.

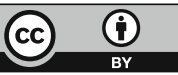

